\title{
The Effect of Dissolved Oxygen on the Growth of Young Silver Bream
}

\author{
Kenji ChIBA \\ (Accepted August 14, 1982)
}

\begin{abstract}
Two experiments were conducted to clarify the effect of dissolved oxygen on the growth of young silver bream (body weight $3-15 \mathrm{~g}$ ).

In experiment $\mathrm{I}$, DO level was controlled by $\mathrm{N}_{2}$ gas bubbling, and young fish were cultured under various DO levels. The growth rate decreased in the thanks in which DO level was less than $60 \%$, and the food conversion efficiency decreased remarkably at the DO level less than $40 \%$. Little growth was observed at DO level $20 \%$.

In experiment II, young fish were cultured under various DO levels and waste substance levels. The experiment comprised of 5 tanks which were arranged in duplicate series. Regardless of the waste substance accumulation, retarded growth was observed only in those thanks in which average DO level was less than $50 \%$. It was considered that the DO decrease was more effective on the growth than the accumulation of $\mathrm{NH}_{4}-\mathrm{N}(1.5 \mathrm{ppm})$.

From the results of these experiments, DO level $60 \%$, at water temperature $23.4-29.8^{\circ} \mathrm{C}$, could be considered the minimum level for young silver bream to maintain a normal and healthy growth.

Four young silver bream culture in ponds, adequate attention should be paid to DO level rather than on the accumulation of waste substance; and DO level should be kept at more than $60 \%$ in air saturation.
\end{abstract}

Dissolved oxygen is an important parameter to be considered in fish culture. Nevertheless previous studies on the effects of dissolved oxygen for fish growth and feeding were concentrated mainly on freshwater fishes. Less attention was given to the study of marine fishes.

In this study the effect of dissolved oxygen on the young silver bream Sparus sarba was examined in view of clarifying the favorable dissolved oxygen level for culture.

\section{Materials and Methods}

\section{Experiment I}

This experiment was carried out from 1972 Aug. 8 to 1973 Sept. 20. The young of silver bream (body weight 3-15 g) captured in June and July in 1972 and 1973 were used as experimental animal. These test animals were kept in the rearing equipment under various dissolved oxygen levels. Complete set-up of the equipment was illustrated in Fig. 1. It was slightly modified from HerrmanN et al. ${ }^{1)}$ and STEWARt et al. ${ }^{2)}$ Continuous supply of seawater was led into a reservior which was provided with aeration facilities. With an overflow pipe fitted to the side of the reservoir, the water level was maintained constantly. Seawater from the reservoir was led into vinyl chloride pipe (B) dimensions $6 \mathrm{~cm}$ in diameter and $120 \mathrm{~cm}$ in length at the rate of 2$2.5 \mathrm{l} / \mathrm{min}$. Simultaneously, $\mathrm{N}_{2}$ gas was introduced into the pipe from the bottom portion at the rate of $0.5-0.8 \mathrm{l} / \mathrm{min}$. Seawater from the vinyl chloride pipe was led into a closed rearing tank (C) by means of connecting pipe made of vinyl chloride. By regulating the flow rate of $\mathrm{N}_{2}$ gas and seawater, dissolved oxygen in the seawater was led through the connecting pipe and kept at the desired level within the range of $20-60 \%$ in air saturation. The seawater with regulated dissolved oxygen was further introduced into the reaing tank $(C)$. The closed rearing tank $(20 \times 20 \times 40 \mathrm{~cm})$ was made of vinyl chloride, with a lid and one side being made transparent to facilitate observation. Between the lid and tank, rubber plate $(2 \mathrm{~mm}$ in thickness) was set and tightened with nuts. On the lid a hole $(3 \mathrm{~cm}$ in diameter) was provided for feeding purposes, and this was usually plugged with a rubber stopper. During feeding time, the water inflow from the connecting pipe was stopped and the rubber plug was removed. Five similar equipments were prepared and a series of experi-

* Fisheries Laboratory, The University of Tokyo, Maisaka, Shizuoka 431-02, Japan. (千菜健治: 東京大学 農学部付属水産実験所) 


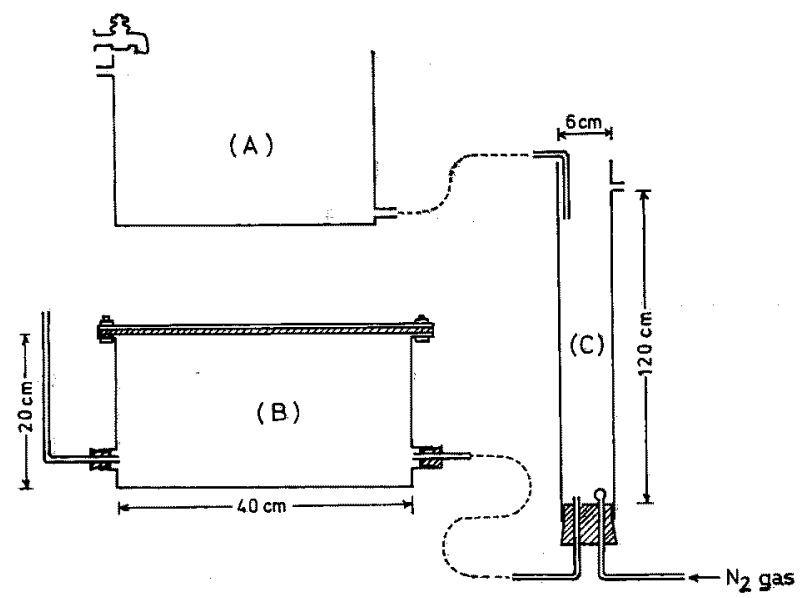

Fig. 1. Fish rearing equipment under various oxygen levels. (A): Water reservoir, (B): Dissolved oxygen regulating tank, (C): Closed rearing tank.

ments were conducted under 5 different dissolved oxygen levels at the same time. Fish were fed three times a day $(9: 00,13: 00$ and $17: 00)$ with crumbled pellet No. 3 for Ayu-fish (supplied by Oriental-Kobo KK). Feed was offered in small quantities while active feeding behavior was observed. The test animals took the sinking feed actively, and also fed on the feed that settled on the bottom. However, the presence of small amount of feed remained at the bottom of tank which was unavoidable.

A series of experiments lasted for 7 or 10 days, with 6 or 9 days feeding respectively. After one day fasting, total length and body weight were measured.

Totally, 13 series of experiments with different fish were carried out.

Temperature, dissolved oxygen and chlorinity in each tank were recorded at 9:00 a.m. before feeding. Before the commencement of experiment dissolved oxygen was measured at the region of the connecting pipe, center of tank, and outlet of rearing tank. It was observed that concentrations of dissolved oxygen at center and outlet showed no significant difference in their levels. Obviously, dissolved oxygen level at inlet was slightly higher as compared to the center and outlet. Therefore, during the process of the experiment dissolved oxygen levels were measured only at the outlet. Diurnal fluctuation of dissolved oxygen was observed several times, throughout the duration of the experiments, but the wide range of fluctuation was not observed.

\section{Experiment II}

This experiment was carried out in 1973 from Aug. 21 to Sept. 17, to compare the effects of low oxygen and high concentration of waste substance.

Five vinyl chloride tanks $(36 \times 52 \times 28 \mathrm{~cm})$ were arranged in duplicate series. Seawater from a reservoir $(36 \times 52 \times 28 \mathrm{~cm})$ was directed into the series by means of two pipes $(1.0 \mathrm{~cm}$ in diameter). Seawater from each tank (45 liter water) was reused instantly with two connecting pipes $(1.0 \mathrm{~cm}$ in diameter) and finally led out. Aeration device were installed in one series (A series) and omitted in the other. Each series were identified as depicted in figure A-1 through A-5. The other series were illustrated as B-1 through B-5. Tanks A-1 and B-1 represented the best environment with the advantage of utilizing water directly from the reservoir. On the contrary, A-5 and B-5 had the disadvantage of utilizing reused water from the previous tanks. Aerated seawater from the reservoir (chlorinity 13.7-18.1\%o) was introduced to the first tanks of each series $(\mathrm{A}-1, \mathrm{~B}-1)$ at the rate of $2.8 \% / \mathrm{min}$. Thus, it was expected that waste substance level increased through No. 1 to No. 5 tanks in both series, but dissolved oxygen level decreased in $\mathbf{B}$ series only.

In each tank 30 individuals of young silver bream (body weight 9-15 g) were stocked and cultured for 4 weeks. Fish were fed three times a day (at 9:00, 13:00 and 17:00). The feed and the manner of feeding were the same as mentioned in experiment $\mathbf{I}$. Water temperature and dis- 
solved oxygen were measured every day at 9:00 before feeding. Once a week diurnal fluctuation of water temperature, dissolved oxygen, ammonium-nitrogen, and nitrite-nitrogen were determined. After 4 weeks, total length and body weight were measured and growth rate and feed conversion efficiency were calculated.

\section{Result}

\section{Experiment I}

The experimental condition and the results of fore-going experiments were shown in Table 1 and 2. Although, the values of growth and feeding rates and the food conversion efficiency were sometimes quite different with each experiment, it could be supposed that in one series of experiment those rates in growth and feeding and food conversion efficiency decreased with the decrease of dissolved oxygen. The difference of initial body weight for each fish in each experiment could be one of the reason for the difference on the growth rates, the feeding rates and food conversion efficiency. Hence, relative value in the growth rate, the feeding rate and food conversion efficiency were calculated from each experiment to compare the values with all the experiments as a whole. Relative values were calculated as follows: - Those values obtained in a tank in which dissolved oxygen level exceeded $75 \%$ in air saturation, relative value was set at 100 in each experiment. When there were more than 2 tanks of which dissolved oxygen exceeded $75 \%$, mean value of those tanks were also set at a relative value 100 . Values of those rates and efficiencies obtained in other tanks were divided by the values of the tank which exceeded $75 \%$ in the experi- ment, and then multiplied by 100 .

These relative values were plotted against oxygen levels in Fig. 2-4. At the same time, by grouping these values according to dissolved oxygen in air saturation interval $10 \%$, the mean values and their $95 \%$ confidence limits were calculated. They were plotted with the limits against the mean values of oxygen level within each of the dissolved oxygen $10 \%$ intervals. Furthermore, for calrifying the relation between the mean values of relative values and oxygen level, the moving average values were calculated from the 3 successive mean values and they were joined by a smooth curve.

Although the plotted relative values against oxygen level were scattered widely in the figures, it could be observed that the decreasing tendencies of growth rate, feeding rate and food conversion efficiency were correlated with the decrease in dissolved oxygen.

Considering the fitted smooth curve, it could be added that the values of relative growth rate were kept nearly at the same level of $90-95 \%$ at the oxygen level $60-85 \%$. These values of relative growth rate decreased with decrease in oxygen level at the oxygen level less than $60 \%$, and especially at the oxygen level less than $40 \%$ they decreased remarkably.

As for the feeding rate, when the fitted curve was considered, it could also be concluded that the relative values decreased with decrease in oxygen level, and at oxygen level less than $40 \%$ they decreased markedly. According to the daily observations, fish showed a poor appetite when the dissolved oxygen was $20.1-21.5 \%$ (WT: 26.5 $28.5^{\circ} \mathrm{C}$ ). This observation clearly indicated that there was a small weight increase in dissolved

Table 1. Details of experiment

\begin{tabular}{|c|c|c|c|c|}
\hline Test No. & Test period & $\begin{array}{c}\text { Water } \\
\text { temperature }{ }^{\circ} \mathrm{C}\end{array}$ & Chlorinity & $\begin{array}{c}\text { Number of fish } \\
\text { in each } \operatorname{tank}\end{array}$ \\
\hline 1 & '72 Aug. $\quad 8-18$ & $26.5-28.8$ & $15.9-17.0$ & 10 \\
\hline 2 & '72 Aug. 19-29 & $25.6-27.5$ & $17.0-17.3$ & 10 \\
\hline 3 & '72 Aug. 30-Sept. 9 & $26.6-28.0$ & $16.6-17.0$ & 10 \\
\hline 4 & '72 Sept. $10-16$ & $24.0-26.5$ & $16.6-17.1$ & 10 \\
\hline 5 & '73 Jul. $7-16$ & $26.8-28.7$ & $17.2-17.4$ & 10 \\
\hline 6 & '73 Jul. $\quad 17-24$ & $26.3-26.9$ & $17.4-17.7$ & 20 \\
\hline 7 & '73 Jul. $\quad 24-31$ & $26.7-26.8$ & $17.7-17.9$ & 20 \\
\hline 8 & '73 Aug. 1-8 & $26.3-29.7$ & $17.9-18.1$ & 20 \\
\hline 9 & '73 Aug. 9-16 & $27.0-29.8$ & $17.8-18.1$ & 20 \\
\hline 10 & '73 Aug. $20-27$ & $26.0-27.9$ & $18.0-18.1$ & 20 \\
\hline 11 & '73 Aug. 28-Sept. 4 & $24.5-27.0$ & $17.9-18.1$ & 20 \\
\hline 12 & '73 Sept. $5-12$ & $23.4-26.6$ & $13.7-18.1$ & 20 \\
\hline 13 & '73 Sept. 13-20 & $23.8-26.7$ & $14.7-18.1$ & 20 \\
\hline
\end{tabular}


Chiba

Table 2. Result of experiment I

\begin{tabular}{|c|c|c|c|c|c|c|c|c|c|c|}
\hline \multirow{2}{*}{$\begin{array}{l}\text { Test } \\
\text { No. }\end{array}$} & \multirow{2}{*}{$\begin{array}{l}\text { Tank } \\
\text { No. }\end{array}$} & \multicolumn{2}{|c|}{$\begin{array}{c}\text { Dissolved Oxygen } \\
(\%)\end{array}$} & \multicolumn{4}{|c|}{$\begin{array}{l}\text { Mean body weight } \\
\text { (g) }\end{array}$} & \multirow{2}{*}{$\begin{array}{l}\text { Growth } \\
\text { rate } \\
(\%)\end{array}$} & \multirow{2}{*}{$\begin{array}{c}\text { Feeding } \\
\text { rate } \\
(\%)\end{array}$} & \multirow{2}{*}{$\begin{array}{c}\text { Food con. } \\
(\%) \\
\text { efficiency }\end{array}$} \\
\hline & & mean & range & initial & sd. & final & sd. & & & \\
\hline \multirow{5}{*}{1} & 1 & 47.6 & $43.7-52.1$ & 4.73 & 0.89 & 6.13 & 1.01 & 29.6 & 7.0 & 42.4 \\
\hline & 2 & 52.9 & $49.5-56.9$ & 4.14 & 0.84 & 6.15 & 1.11 & 48.6 & 8.7 & 54.2 \\
\hline & 3 & 74.4 & $69.0-82.9$ & 4.17 & 0.19 & 6.27 & 1.05 & 50.4 & 10.4 & 48.3 \\
\hline & 4 & 78.2 & $73.1-81.2$ & 3.78 & 0.86 & 5.63 & 1.08 & 48.9 & 11.4 & 43.0 \\
\hline & 5 & 80.0 & $77.5-85.2$ & 4.01 & 0.90 & 6.30 & 1.20 & 57.1 & 12.2 & 44.8 \\
\hline \multirow{4}{*}{2} & 1 & 49.3 & $47.2-54.9$ & 6.13 & 1.01 & 7.49 & 1.21 & 22.2 & 3.8 & 57.9 \\
\hline & 2 & 64.3 & $59.2-70.2$ & 6.27 & 1.11 & 8.23 & 1.39 & 31.3 & 4.9 & 64.1 \\
\hline & 3 & 78.0 & $74.1-84.3$ & 5.63 & 1.05 & 7.84 & 1.24 & 39.3 & 5.7 & 69.1 \\
\hline & 4 & 80.7 & $79.2-83.2$ & 6.30 & 1.20 & 8.40 & 1.36 & 33.3 & 5.7 & 59.0 \\
\hline \multirow{5}{*}{3} & 1 & 31.0 & $24.6-34.8$ & 8.23 & 1.39 & 9.87 & 1.62 & 19.9 & 4.3 & 46.6 \\
\hline & 2 & 42.3 & $34.3-47.9$ & 7.49 & 1.21 & 9.63 & 1.51 & 28.6 & 4.3 & 67.1 \\
\hline & 3 & 46.3 & $42.0-50.4$ & 8.15 & 1.29 & 10.79 & 1.49 & 32.4 & 4.4 & 73.3 \\
\hline & 4 & 78.2 & $72.4-81.2$ & 7.48 & 1.24 & 10.79 & 1.35 & 39.2 & 6.2 & 64.3 \\
\hline & 5 & 78.6 & $71.5-80.1$ & 8.40 & 1.36 & 11.72 & 1.53 & 39.5 & 6.6 & 60.0 \\
\hline \multirow{4}{*}{4} & 1 & 68.4 & $67.9-75.7$ & 10.79 & 1.49 & 12.68 & 1.86 & 17.5 & 3.5 & 84.4 \\
\hline & 2 & 46.9 & $41.4-50.1$ & 11.83 & 1.64 & 13.02 & 1.89 & 10.1 & 2.9 & 56.9 \\
\hline & 3 & 86.1 & $82.5-87.7$ & 10.79 & 1.49 & 12.99 & 1.76 & 18.4 & 4.7 & 64.7 \\
\hline & 4 & 84.6 & $82.9-88.8$ & 11.72 & 1.53 & 14.36 & 1.81 & 22.5 & 4.1 & 92.0 \\
\hline \multirow{5}{*}{5} & 1 & 33.4 & $28.6-35.9$ & 4.21 & 1.34 & 4.96 & 1.46 & 17.8 & 5.2 & 57.7 \\
\hline & 2 & 51.3 & $45.6-60.2$ & 4.42 & 0.92 & 5.59 & 1.12 & 26.5 & 5.7 & 78.0 \\
\hline & 3 & 68.0 & $62.9-72.8$ & 4.04 & 0.91 & 4.84 & 1.00 & 19.8 & 6.4 & 51.9 \\
\hline & 4 & 82.0 & $76.9-86.8$ & 4.38 & 0.87 & 5.47 & 1.18 & 24.9 & 6.9 & 59.9 \\
\hline & 5 & 81.9 & $75.3-85.8$ & 4.38 & 1.11 & 5.29 & 1.22 & 20.8 & 7.9 & 43.8 \\
\hline \multirow{5}{*}{6} & 1 & 35.4 & $29.2-43.5$ & 4.86 & 1.56 & 5.64 & 1.57 & 16.1 & 5.5 & 48.4 \\
\hline & 2 & 41.6 & $35.8-47.6$ & 5.19 & 1.04 & 6.51 & 1.36 & 25.3 & 6.1 & 68.9 \\
\hline & 3 & 62.2 & $58.6-69.6$ & 4.83 & 1.08 & 6.29 & 1.29 & 30.2 & 7.9 & 63.8 \\
\hline & 4 & 79.6 & $75.9-83.3$ & 5.73 & 1.10 & 6.94 & 1.45 & 31.6 & 7.9 & 66.6 \\
\hline & 5 & 82.4 & $78.2-85.5$ & 4.83 & 1.11 & 6.22 & 1.33 & 28.8 & 9.4 & 51.4 \\
\hline \multirow{5}{*}{7} & 1 & 33.0 & $28.1-39.2$ & 5.64 & 1.57 & 6.98 & 1.76 & 23.9 & 6.1 & 65.8 \\
\hline & 2 & 30.9 & $26.3-36.1$ & 6.51 & 1.36 & 7.91 & 1.64 & 21.6 & 5.4 & 67.2 \\
\hline & 3 & 58.8 & $55.7-59.2$ & 6.29 & 1.29 & 8.13 & 1.49 & 29.2 & 6.9 & 70.7 \\
\hline & 4 & 75.7 & $74.5-79.4$ & 6.94 & 1.45 & 9.04 & 1.89 & 30.3 & 6.9 & 64.7 \\
\hline & 5 & 78.4 & $75.9-82.9$ & 6.22 & 1.33 & 7.83 & 1.52 & 26.0 & 8.3 & 52.5 \\
\hline \multirow{5}{*}{8} & 1 & 33.0 & $27.2-37.3$ & 7.68 & 2.15 & 8.72 & 2.27 & 13.6 & 4.1 & 54.9 \\
\hline & 2 & 23.2 & 20.9-28.9 & 7.74 & 1.56 & 7.94 & 1.52 & 2.6 & 2.0 & 21.2 \\
\hline & 3 & 57.9 & $54.3-63.9$ & 7.38 & 1.84 & 9.08 & 2.13 & 23.1 & 5.2 & 74.1 \\
\hline & 4 & 75.5 & $74.1-78.3$ & 7.55 & 1.78 & 8.81 & 2.00 & 16.6 & 4.8 & 57.7 \\
\hline & 5 & 82.9 & $78.3-87.6$ & 7.59 & 1.91 & 9.19 & 2.07 & 21.2 & 6.3 & 55.9 \\
\hline \multirow{5}{*}{9} & 1 & 24.9 & $19.8-28.8$ & 8.91 & 1.96 & 9.70 & 2.02 & 8.9 & 3.5 & 42.5 \\
\hline & 2 & 18.7 & $17.2-21.1$ & 8.70 & 1.68 & 8.79 & 1.83 & 1.0 & 2.1 & 8.3 \\
\hline & 3 & 51.3 & $43.5-56.0$ & 8.13 & 2.06 & 9.45 & 2.63 & 16.2 & 4.7 & 57.4 \\
\hline & 4 & 65.6 & $62.1-70.8$ & 9.01 & 2.32 & 10.19 & 2.41 & 13.1 & 4.6 & 65.5 \\
\hline & 5 & 79.9 & $77.5-82.9$ & 9.08 & 2.10 & 10.65 & 2.23 & 17.3 & 5.3 & 54.6 \\
\hline \multirow{5}{*}{10} & 1 & 46.8 & $42.7-47.5$ & 7.82 & 1.05 & 8.59 & 1.09 & 9.7 & 4.4 & 37.3 \\
\hline & 2 & 24.0 & $19.3-29.9$ & 7.83 & 1.05 & 7.87 & 1.32 & 0.5 & 2.0 & 5.4 \\
\hline & 3 & 44.9 & $38.1-48.7$ & 7.38 & 0.89 & 8.11 & 1.02 & 9.0 & 4.3 & 38.1 \\
\hline & 4 & 72.9 & $67.8-75.8$ & 7.62 & 1.00 & 8.68 & 1.21 & 13.9 & 5.0 & 46.2 \\
\hline & 5 & 85.3 & $83.9-88.1$ & 7.27 & 0.70 & 9.43 & 0.89 & 14.0 & 60 & 38.3 \\
\hline
\end{tabular}


Table 2. (Continued).

\begin{tabular}{|c|c|c|c|c|c|c|c|c|c|c|}
\hline \multirow{2}{*}{$\begin{array}{c}\text { Test } \\
\text { No. }\end{array}$} & \multirow{2}{*}{$\begin{array}{l}\text { Tank } \\
\text { No. }\end{array}$} & \multicolumn{2}{|c|}{$\begin{array}{c}\text { Dissolved Oxygen } \\
(\%)\end{array}$} & \multicolumn{4}{|c|}{$\begin{array}{l}\text { Mean body weight } \\
(\mathrm{g})\end{array}$} & \multirow{2}{*}{$\begin{array}{c}\text { Growth } \\
\text { rate } \\
(\%)\end{array}$} & \multirow{2}{*}{$\begin{array}{c}\text { Feeding } \\
\text { rate } \\
(\%)\end{array}$} & \multirow{2}{*}{$\begin{array}{c}\text { Food con } \\
(\%) \\
\text { efficiency }\end{array}$} \\
\hline & & mean & range & initial & sd. & final & sd. & & & \\
\hline \multirow{5}{*}{11} & 1 & 47.1 & $42.5-53.9$ & 8.53 & 1.25 & 9.61 & 1.33 & 12.3 & 3.8 & 55.1 \\
\hline & 2 & 23.5 & $23.3-26.4$ & 8.59 & 1.20 & 8.94 & 1.15 & 4.1 & 3.8 & 37.4 \\
\hline & 3 & 46.4 & $43.8-50.2$ & 8.48 & 1.16 & 9.42 & 1.16 & 11.1 & 3.5 & 52.7 \\
\hline & 4 & 77.2 & $76.1-78.3$ & 8.99 & 1.22 & 9.99 & 1.46 & 11.1 & 3.9 & 48.0 \\
\hline & 5 & 83.3 & $82.4-84.3$ & 8.84 & 1.27 & 10.24 & 1.61 & 15.8 & 5.0 & 53.0 \\
\hline \multirow{5}{*}{12} & 1 & 38.7 & $34.0-44.5$ & 9.43 & 1.62 & 10.56 & 1.80 & 12.0 & 3.8 & 53.1 \\
\hline & 2 & 23.9 & $21.9-29.7$ & 9.72 & 1.37 & 10.25 & 1.43 & 5.5 & 2.0 & 45.5 \\
\hline & 3 & 43.1 & $40.4-49.6$ & 9.56 & 1.59 & 10.86 & 1.80 & 13.6 & 3.6 & 63.9 \\
\hline & 4 & 74.9 & $72.1-77.0$ & 9.46 & 1.17 & 10.44 & 1.26 & 10.4 & 3.3 & 51.9 \\
\hline & 5 & 84.5 & $80.9-85.5$ & 9.65 & 1.39 & 10.86 & 1.71 & 12.5 & 4.6 & 45.2 \\
\hline \multirow{5}{*}{13} & 1 & 37.3 & $34.0-39.5$ & 10.46 & 1.94 & 11.63 & 2.20 & 11.2 & 3.0 & 62.7 \\
\hline & 2 & 23.8 & $20.8-25.5$ & 10.87 & 1.59 & 11.34 & 1.60 & 4.3 & 1.6 & 43.6 \\
\hline & 3 & 43.5 & $39.7-48.9$ & 10.45 & 1.55 & 11.76 & 1.88 & 12.5 & 2.8 & 75.9 \\
\hline & 4 & 79.1 & $74.2-85.7$ & 10.86 & 1.24 & 12.16 & 1.41 & 12.0 & 3.0 & 65.7 \\
\hline & 5 & 84.6 & $81.0-86.1$ & 10.36 & 1.69 & 11.63 & 1.68 & 12.3 & 4.1 & 50.3 \\
\hline
\end{tabular}

Growth rate was calculated from the initial and final mean body weight. Feeding rate was calculated as follows: Average amount of consumed feed for one day by one fish was divided by mean initial body weight and multiplied by 100 . Feed conversion efficiency was calculated as the percentage of total weight gain to total amount of given feed.



Fig. 2. Relation between relative growth rate and dissolved oxygen level in air saturation.

White circle with limits means the average value of relative growth rate and it's $95 \%$ confidence limits in each $10 \%$ DO interval.

A smooth curve was obtained by joining the moving average of average values of relative growth rate in each $10 \% \mathrm{DO}$ interval.

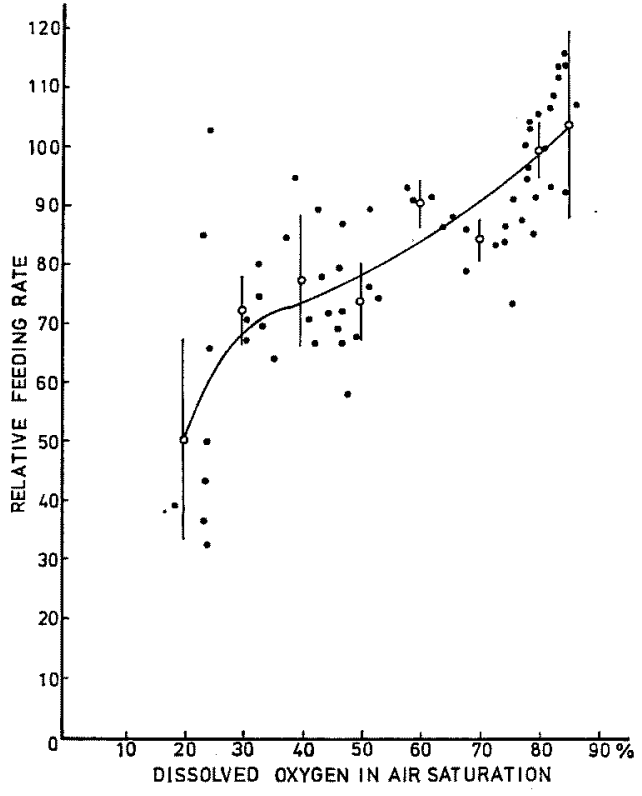

Fig. 3. Relation between relative feeding rate and dissolved oxygen level in air saturation.

White circle with limits means the average value of relative feeding rate and it's $95 \%$ confidence limits in each $10 \%$ DO interval. A smooth curve was obtained by joining moving averages of average values of relative feeding rates in each $10 \%$ DO interval. 


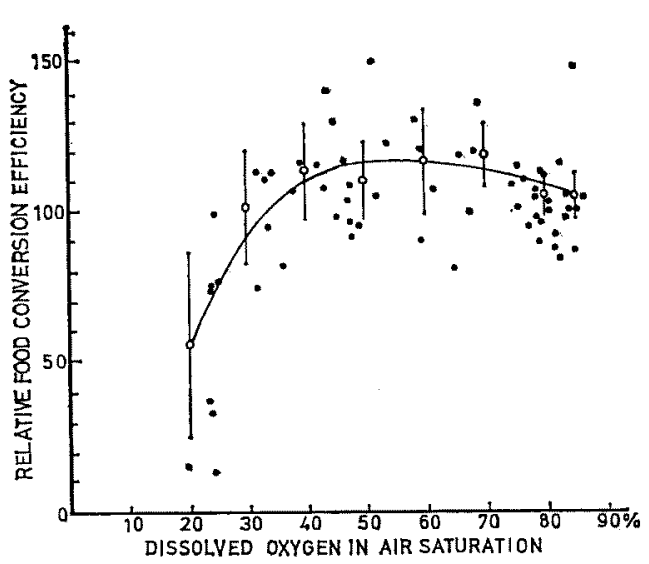

Fig. 4. Relation between relative food conversion efficiency and dissolved oxygen level in air saturation.

White circle with limits means the average value of relative food conversion efficiency and it's $95 \%$ confidence limits in each DO $10 \%$ interval. A smoooth curve was obtained by joining the moving average of average values of relative food conversion efficiency in each $10 \%$ DO interval.



Fig. 5. Relation between respiratory rate and dissolved oxygen level in air saturation.

White circle with limits means the average value of respiratory rates and it's $95 \%$ confidence limits in each $10 \%$ DO interval. A smooth curve was obtained by joining the moving average values of respiratory rate in each $10 \%$ DO interval.

oxygen level about $20 \%$.

As to food conversion efficiency, it was found that the relative values maintained nearly at the same level at the oxygen level more than $40 \%$ and they showed remarkable decrease at the oxygen level less than $40 \%$ with the consideration of fitted curve.

The respiratory rates which were observed in experiments No. 9 and No. 12 were illustrated in Fig. 5. In the same manner with the case of growth rate, the mean values of respiraotry rates within $10 \%$ dissolved oxygen interval were plotted with $95 \%$ confidence limits. Observations showed that there was a clear correlation of increasing tendency of respiration rates with decrease of dissolved oxygen. At the oxygen level between $60-80 \%$ the respiration rates were kept nearly at the same level, and at the oxygen level less than $60 \%$ they increased with the decrease in oxygen level. Especially at the oxygen level less than $50 \%$, the increase of respiratory rate was remarkable. This dissolved oxygen level 50-60\%, at which the respiratory rates started to increase, was almost the same in level during the initiation of the decrease in growth rate.

\section{Experiment II}

The results of experiment II were summarized in Table 3. As for dissolved oxygen, the oxygen concentrations decreased in downstream tanks, and the decrease was more remarkable in $\mathbf{B}$ series thanks only. On the contrary, ammoniumnitrogen concentrations increased in downstream tanks in both $\mathrm{A}$ and $\mathrm{B}$ series. These decrease in dissolved oxygen and increase in ammoniumnitrogen in downstream tanks became greater as the rearing time proceeded.

Based on the observations of diurnal fluctuation of dissolved oxygen and ammonium-nitrogen, high dissolved oxygen and low ammonium-nitrogen concentrations were observed in the morning before feeding. With the commencement of feeding, the decrease in oxygen level and the increase of ammonium-nitrogen were observed. Ammonium-nitrogen reached the maximum level at 18:00 o'clock while dissolved oxygen reached the minimum level at the same time. These maximum and minimum values varied depending on the arrangement of the tanks. Average values of dissolved oxygen and maximum values of ammonium-nitrogen and nitrite-nitrogen observed in each tanks were shown in Table 3. The average values of dissolved oxygen at 9:00, 13:00 and 18:00 were calculated from four diurnal fluctuation observations, and maximum and minimum values of ammonium-nitrogen and nitrite-nitrogen were obtained from the results of final week 


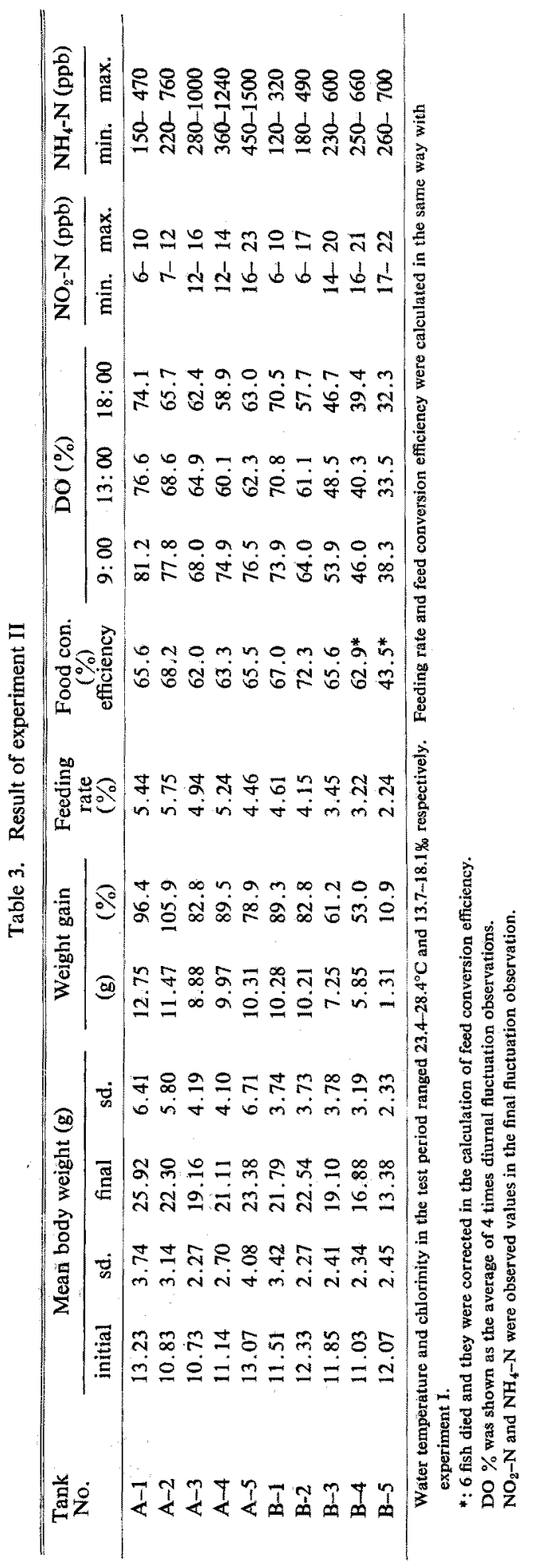


observation. The fluctuation of ammoniumnitrogen was highest in the 4th week observations. According to the results of four observations that were conducted, the dissolved oxygen level at 13:00 was near to the average of observed values in diurnal fluctuation in each tank. The ammonium-nitrogen levels in the downstream tanks of A series were often much higher when compared to those of tanks in B series in the latter half of culturing period. The reason for the presence of higher ammonium-nitrogen levels in A series tanks could be attributed to the fact that higher growth rates in A series were observed. Under such circumstances, the amount of fish stocked in A series tanks became higher than in B series tanks.

Among B series tanks maximum and minimum growth rates were recorded $89.3 \%$ in uppermost stream No. 1 tank and $10.9 \%$ in lowermost No. 5 tank respectively. The decreasing tendency of growth rate was observed from up- to downstream tanks. On the other hand in series $A$ no clear decreasing tendencies in growth rate among tanks were observed, even though maximum and minimum growth rates were observed $105.9 \%$ in No. 2 tank and $78.9 \%$ in No. 5 tank respectively. Growth rate in A-5 tank was not so low as compared to that A-1 tank $96.4 \%$.

Concentrations of ammonium-nitrogen $\left(\mathrm{NH}_{4}-\right.$ N) $1.5 \mathrm{ppm}$ and calculated un-ionized ammonia ${ }^{\text {s) }}$ $\left(\mathrm{NH}_{8}-\mathrm{N}\right) \quad 0.07 \mathrm{ppm}$ (WT: $24.5^{\circ} \mathrm{C}, \mathrm{pH}: \quad 8.0$, chlorinity: $15.5 \%$ in $\mathrm{A}-1$ tank were higher when compared to those in B-4 and B-5 tanks. At present no information was available on the effect of ammonium-nitrogen and un-ionized ammonia levels on appetite and growth in this species, but these ammonium-nitrogen and un-ionized ammonia levels were not affective on appetite or growth in other species, such as channel catfish, ${ }^{4-\delta)}$ coho salmon, ${ }^{8)}$ cutthroat, ${ }^{\text {,) }}$ Dover sole and trout. ${ }^{8)}$

Therefore the retarded growth in downstream tanks in B series might be caused by the decreased oxygen level and not precisely by the increase in ammonium-nitrogen level.

Distinct retardation in growth were recorded in tanks with dissolved oxygen at 13:00 less than $40 \%$, such as $\mathrm{B}-4$ and $\mathrm{B}-5$, and slight retardation in growth was observed in B-3 tank with slightly higher oxygen level $48.5 \%$ at 13:00. This phenomena corresponded to the result of experiment $\mathrm{I}$.

\section{Discussion}

Up to the present, several experiments had been conducted on the effect of dissolved oxygen on the growth of fishes, such as carp, ${ }^{8)}$ coho salmon, ${ }^{1)}$ largemouth bass, ${ }^{2)}$ and so on. ${ }^{10,11)}$ In the above mentioned papers, it was reported that at less than a certain level of dissolved oxygen, the growth rate, feeding rate and food conversion efficiency decreased with the decrease of oxygen. This level was recognized as the minimum level for normal life of fishes (ITAZAWA). ${ }^{12)}$ Although it varied with species of fish, generally it is within the range of $40-50 \%$. FRY ${ }^{18)}$ and SwrFT ${ }^{14)}$ suggested that growth was restricted by the ability of respiratory system to uptake oxygen from ambient water. BRETT, ${ }^{15)}$ KUTTX $^{16)}$ and DahLBerg et $a .^{17)}$ reported that active metabolism was restricted by available oxygen. In both the above mentioned cases it remained similar in point that the cause of retarded growth or failure to continue swimming was due to the insufficient supply of oxygen to be uptaken by respiratory system of the fish from ambient water. ITAZAWA ${ }^{12)}$ reported that the minimum level of dissolved oxygen in water required for maintenance of oxygen content of arterial blood at the normal level amlost coincided with the minimum oxygen level required for normal growth in eel, carp and rainbow trout. Furthermore, NAKANISHI et al. ${ }^{18)}$ also reported that the respiratory rate and it's stroke increased and heart beat rate decreased contrastedly with the decrease of dissolved oxygen when it was less than the required level for maintenance of oxygen content of arterial blood at normal level. These increase in respiratory rate and stroke of operculum and decrease of heart beat rate were considered reactions of the animal to decreasing dissolved oxygen for maintaining the oxygen content in arterial blood at normal level.

In this study with silver bream, similar results were obtained with those fishes ${ }^{1-2,9-11)}$ mentioned above in relation to oxygen. The growth rate, feeding rate and food conversion efficiency were expressed in relative value and indicated a decreasing tendency with the decrease of dissolved oxygen. Especially, growth rate and food conversion efficiency decreased at the oxygen level less than $60 \%$ and $40 \%$ respectively and above these levels those values maintained nearly the same. Consequently, under $60 \%$ level the young of silver bream could not keep the oxygen level in arterial blood at normal level. Furthermore, oxygen which was furnished by the respiratory 
system could not satisfy the demand by the organs and tissues in fish body. In addition, increase of respiratory rate under dissolved oxygen $60 \%$ level could be considered a compelled performance to keep normal oxygen level in blood. Therefore, this dissolved oxygen level might be considered as minimum dissolved oxygen level for normal growth in the young of silver bream and was about $60 \%$ in air saturation.

As for the food conversion efficiency, decreasing tendency was observed under $40 \%$. The food conversion efficiency is expressed as the ratio of weight gain to feed given, and food conversion efficiency is influenced by the digestability, assimilation rate or fish activity etc.. As the amount of feed maintenacne was influenced mainly by water temperature, it is presumed to be nearly the same in any dissolved oxygen level. Therefore, this decreasing level of food conversion efficiency under $40 \%$ was caused by decreasing the feeding rate. The effect of dissolved oxygen on digestability and assimilating rate should be considered in future study. At the oxygen level $80-85 \%$ the relative values showed slight decrease in comparison with values at dissolved oxygen $70 \%$. This reason could be attributed to the fact that a larger amount of uneaten feed remained at the bottom of the tank as compared to other tanks with lower oxygen levels. In the tanks with oxygen level $80-85 \%$, animals showed more active feeding behavior than others and sometimes excess feed could be offered.

In experiment $\mathrm{I}$, dissolved oxygen level was regulated by bubbling with nitrogen gas. ITAZAWA et $a .^{19)}$ and TAKEDA et $a .^{20)}$ reported that the minimum level of ambient oxygen required for maintenace of oxygen concentration in the aerterial blood was affected by $\mathrm{CO}_{2}$ concentration in crap. In experiment $\mathrm{I}, \mathrm{pH}$ values in outlets indicated no significant differences in each of the tanks. Carbon dioxide level was estimated $0.05-0.1 \mathrm{ppm}$ from water temperature, $\mathrm{pH}$ value and alkalinity ${ }^{21)}$. It was thus presumed that this range of $\mathrm{CO}_{2}$ has no significant effect on the fish. In this experiment oxygen was regulated with $\mathrm{N}_{2}$ gas and the minimum dissolved oxygen level for normal growth was considered $60 \%$ in air saturation. In intensive fish culture ponds there is some possibility of $\mathrm{CO}_{2}$ increase in the water. This effect of $\mathrm{CO}_{2}$ on the minimum dissolved oxgyen for normal growth could be an important criteria for further study. From the results of experiment II, it is supposed that under the conditions of ammonium-nitrogen concentration less than
$1.5 \mathrm{ppm}$ (un-ionized ammonia $0.07 \mathrm{ppm}$ ), the decrease of dissolved oxygen was more effective than the increase of ammonium-nitrogen level. Furthermore, at dissolved oxygen level less than about $50 \%$, growth rate and feeding rate decreased. In experiment I, oxygen level in each test tank was adjusted at nearly constant levels. On the contrary, in experiment II oxygen levels in the tanks showed wide range of fluctuations. In the present study, the relation between oxygen level and growth rate was discussed only with the average oxygen values. Therefore, further research is required to elucidate how fluctuations in dissolved oxygen might effect the fish growth.

From these results as observed in experiment I and II, it can be concluded that for the culture of young silver bream, dissolved oxygen level in the pond water should be kept at more than $60 \%$ in air saturation. Adequate studies should be considered and clarified on the effective levels of ammonium-nitrogen and $\mathrm{CO}_{2}$ increase in fish culture ponds in combination with dissolved oxygen levels. Other associating factors which could be directly or indirectly involved or in combination will be a vital factor on water quality study for the healthy growth and maintenace of fish.

\section{References}

1) R. B. Herrmann, C. E. Warren, and P. DoudoROFF: Trans. Am. Fish. Soc., 91, 155-167 (1972).

2) N. E. Stewart, D. L. Shumway, and P. DoudoROFF: J. Fish. Res. Bd. Canada, 24, 475-494 (1967).

3) C. E. Bower: J. Fish. Res. Bd. Canada, 35, 1012-1016 (1978).

4) G. L. KNEPP and G. F. Arkin: P.F.C., 35, 221224 (1973).

5) H. R. RoBINETTE: P.F.C., 38, 26-29 (1976).

6) J. A. BUCKLEY: P.F.C., 40, 30-33 (1978).

7) R. V. Thurston, R. C. Russo, and C. E. Smith: Trans. Am. Fish. Soc., 107, 361-368 (1978).

8) R. Alderson: Aquaculture. 17, 291-301 (1979).

9) K. ChiBA: Bull. Freshwater Fish. Res. Lab., 15, 35-47 (1965).

10) I. R. Adelman and L. L. SMIth: P.F.C., 32, 93$96(1970)$.

11) D. R. SwIFT: Trans. Am. Fish. Soc., 92, 300-301 (1963).

12) Y. Itazawa: Bull. Japan. Soc. Sci. Fish., 37, 273-276 (1971).

13) F. E. J. FRY: The aquatic respiration of fish. In "The physiology of fishes", Vol. 1. (Ed. by M. E. Brown), Academic Press Inc., New York, 1957, pp. 1-63.

14) D. R. SwifT: J. Exp. Biol., 38, 595-604 (1961). 
15) J. R. Brett: J. Fish. Res. Bd. Canada, 21, 11831226 (1964).

16) M. N. Kutry: Can.J. Zool,, 46, 647-653 (1968).

17) M. L. Dahlberg, D. L. Shumway, and P. DoudoROFF: J. Fish. Bd. Canada, 25, 49-70 (1968).

18) T. Nakantshi and Y. Itazawa: Rept. Fish. Res. Lab. Kyushu Univ. 2, 41-52 (1974).

19) Y. ITAZAWA and T. TAKedA: Bull. Japan. Soc. Sci. Fish., 45, 323-327 (1979).
20) T. TAKedA and Y. ItazaWA: Bull. Japan. Soc. Sci. Fish., 45, 329-333 (1979).

21) J. D. H. Stricland and T. R. Parsons: Determination of carbonate, bicarbonate, and free carbon dioxide from $\mathrm{pH}$ and alkalinity measurements, in A practical handbook of seawater analysis. Bulletin, 167, Fish. Res. Bd. Canada, Ottawa, 1968, pp. 27-34. 